University of Nebraska - Lincoln

DigitalCommons@University of Nebraska - Lincoln

West Central Research and Extension Center, North Platte

Agricultural Research Division of IANR

2014

Bioeconomic factors of beef heifer maturity to consider when establishing criteria to optimally select and/or retain herd replacements

\author{
M. C. Stockton \\ R. K. Wilson \\ University of Nebraska-Lincoln, rwilson6@unl.edu \\ D. M. Feuz \\ Utah State University \\ L. A. Stalker \\ University of Nebraska West Central Research and Extension Center, North Platte \\ R. N. Funston \\ University of Nebraska-Lincoln, rick.funston@unl.edu
}

University of Nebraska West Central Research and Extension Center, North Platte, matt.stockton@unl.edu

Follow this and additional works at: https://digitalcommons.unl.edu/westcentresext

Part of the Agriculture Commons, Ecology and Evolutionary Biology Commons, and the Plant Sciences Commons

Stockton, M. C.; Wilson, R. K.; Feuz, D. M.; Stalker, L. A.; and Funston, R. N., "Bioeconomic factors of beef heifer maturity to consider when establishing criteria to optimally select and/or retain herd replacements" (2014). West Central Research and Extension Center, North Platte. 106.

https://digitalcommons.unl.edu/westcentresext/106

This Article is brought to you for free and open access by the Agricultural Research Division of IANR at DigitalCommons@University of Nebraska - Lincoln. It has been accepted for inclusion in West Central Research and Extension Center, North Platte by an authorized administrator of DigitalCommons@University of Nebraska Lincoln. 


\title{
Bioeconomic factors of beef heifer maturity to consider when establishing criteria to optimally select and/or retain herd replacements
}

\author{
M. C. Stockton, ${ }^{1}$ R. K. Wilson, $†$ D. M. Feuz, $\$$ L. A. Stalker,* and R. N. Funston* \\ *University of Nebraska West Central Research and Extension Center, North Platte 69101; †University of Nebraska- \\ Lincoln, Department of Agricultural Economics, Lincoln 68583; and \$Utah State University, Department of \\ Agricultural Economics, Logan 84322
}

\begin{abstract}
Understanding the biology of heifer maturity and its relationship to calving difficulty and subsequent breeding success is a vital step in building a bioeconomic model to identify optimal production and profitability. A limited dependent variable probit model is used to quantify the responses among heifer maturities, measured by a maturity index (MI), on dystocia and second pregnancy. The MI account for heifer age, birth BW, prebreeding BW, nutrition level, and dam size and age and is found to be inversely related to dystocia occurrence. On average there is a $2.2 \%$ increase in the probability of dystocia with every 1 point drop in the MI between the MI scores of 50 and 70. Statistically, MI does not directly alter second pregnancy rate; however, dystocia does. The presence of
\end{abstract}

dystocia reduced second pregnancy rates by $10.67 \%$. Using the probability of dystocia predicted from the MI in the sample, it is found that on average, every 1 point increase in MI added $0.62 \%$ to the probability of the occurrence of second pregnancy over the range represented by the data. Relationships among MI, dystocia, and second pregnancy are nonlinear and exhibit diminishing marginal effects. These relationships indicate optimal production and profitability occur at varying maturities, which are altered by animal type, economic environment, production system, and management regime. With these captured relationships, any single group of heifers may be ranked by profitability given their physical characteristics and the applicable production, management, and economic conditions.

Key words: beef heifer, bioeconomic model, dystocia, maturity, replacement, second pregnancy

(C) 2014 American Society of Animal Science. All rights reserved.

J. Anim. Sci. 2014.92:4733-4740 doi:10.2527/jas2014-8010

\section{INTRODUCTION}

Cammack et al. (2009, p. 517) wrote, "Biological and economic efficiencies of cow-calf production are largely dependent on successful reproduction." The literature is replete with works about reproduction, dystocia, and maturity. Bellows et al. (1971) used ordinary least squares (OLS) regression to quantify the effect of physical size on 4 degrees of dystocia. Morrison et al. (1985) and Basarab et al. (1993) proposed using a discriminant analysis methodology. While similar to OLS, this method optimizes a different objective function giving the estimates of the coefficients an altered meaning and use. In seeking a method to optimize productivity

\footnotetext{
${ }^{1}$ Corresponding author: mstockton2@unl.edu

Received April 30, 2014.

Accepted July 29, 2014.
}

and identify the control variables for reproduction efficiency, Greer et al. (1983) developed an "index of maturity." Their index values proved to be less than statistically significant. More recently, work by Patterson et al. (1992) using target weight (TW) has become a widely accepted method to forecast maturity and initiate heifer breeding. Using the same metric, Feuz (1991) developed a profit function.

As Feuz (1991) recognized, the economically optimal breeding readiness of beef replacement heifers is that point of development where costs are less than or equal to expected revenues obtained by such development. Costs and revenues are dependent on both physical and economic factors used in producing beef cattle, and any model used to accurately reflect profitability/ productivity must include both. In a step toward this end, the maturity index (MI) developed by Stockton et al. (2013) is used to transform observed physical sam- 
ple information into usable dystocia and second pregnancy input/output relationships or response functions (Kay 1981). The nature of these response functions provides structure to the economic relationships and, when appropriately applied, may be used to form objective functions such as a profit equation.

\section{MATERIAL AND METHODS}

In a review of the literature, Zaborski et al. (2009) categorizes dystocia into 4 groups. These categories are further divided into individual causes totaling 21 different factors. Only those factors relevant to the occurrence of dystocia and its relationship to second pregnancy with respect to heifer maturity are considered here.

Two systems used to indicate breeding readiness (defined here as maturity), measured by the MI proposed by Stockton et al. (2013) and the TW approach as outlined by Patterson et al. (1992), are tested as predictors of dystocia. This comparison is a step forward in building a systems model to determine the bioeconomic optimal maturity of heifers.

Currently, the most common method used in forecasting reproductive maturity and future productivity is the TW approach. This method is simple and straightforward and requires only 2 pieces of information: heifer BW at the time of first breeding and average mature BW for either the herd or breed of the heifer. The TW method is based on an average mature BW for a group of animals assumed to reflect the same characteristics as the heifer. This measure is substituted into the calculation since the heifer's true mature BW cannot be known until long after first parity. More recently, Stockton et al. (2013) introduced the MI, which incorporates additional animal-specific information and characteristics. The MI uses heifer BW at breeding, dam mature BW, dam age, heifer breeding age and birth weight, and nutrition level before breeding (Eq. [11]). Unlike TW, MI uses only known information that is observable before breeding. The addition of factors other than prebreeding weight provides key information to the MI making it a measure of maturity based on more than just size.

The current thinking is that maturity, whether measured by MI or TW, is inversely related to dystocia with a yet-to-be-tested and specified relationship to second pregnancy. As maturity increases, the likelihood of dystocia is thought to decrease and become asymptotic to some natural rate. Patterson et al. (1991) suggested that heifers that are smaller at calving experience greater incidence of calving difficulty.

Biological data used in this analysis was collected at the University of Nebraska-Lincoln, Gudmundsen Sandhills Laboratory, and represents 2 consecutive investigations (Funston and Deutscher, 2004; Martin et al., 2008), which are combined into a single data set ( $n$ $=500$ ). Heifers from the earlier study were a composite breed of 25\% Hereford, 25\% Angus, 25\% Simmental, and $25 \%$ Gelbviech. The later study heifers were from the same composite females bred to the Husker Red composite males, which are approximately $75 \%$ Red Angus with either 25\% Simmental or Gelbviech. Both studies are continuous in time and used the same management regime designed to capture the difference in pregnancy rates based on average TW scores at the time of breeding. The earlier study included 240 heifers retained as replacements in 1997, 1998, and 1999, whereas 260 heifers in the latter study were retained in 2000, 2001, and 2002.

The combined data set includes each replacement heifer's identification number, birth weight, birth date, weaning weight, and prebreeding $\mathrm{BW}$ and $\mathrm{BCS}$; dam BW; heifer pregnancy status at first pregnancy diagnosis; heifer BW, BCS, and pregnancy status at second pregnancy diagnosis; and weaning weight of her first calf. When a heifer was removed from the study prematurely, the subsequent information was recorded as null. Dummy, control, or indicator variables are created from the data set to designate the feed treatment and management change groups that heifers were assigned during their development.

For the purposes of this study, factors not related to maturity are assumed to be held constant or randomly distributed among animals. One such random effect is the bulls used for breeding the heifers. These bulls varied by individual animal over time but met the criteria as safe to use on first time calving heifers.

\section{Modeling Dystocia and Second Pregnancy Rates}

A series of probit regression models (Griffiths et al., 1993; Gujarati, 2003), a type of limited dependent variable model, are used to capture the effects of maturity on dystocia and second pregnancy. This type of model limits the predicted or dependent variable to a specific range, in this case between 0 and 1 , where 0 represents a nonoccurrence of dystocia or second pregnancy diagnosis and 1 indicates an occurrence. While the actual observations are binary, identified as happening or not, the predicted outcomes are expressed as a portion of the area under a distribution and are discretely continuous between 0 and 1 .

As a predictive model, all of the values within the 0 to 1 range are interpreted as probabilities. These values are mapped on the vertical axis of a normal cumulative distribution function (CDF). A sample distribution is shown in Fig. 1. This modeling technique has been applied in numerous animal science studies. For example, Doyle et al. (2000), Eler et al. (2002), and Evans et al. (1999) studied factors that affect cow pregnancy. More recently, Hadley et al. (2006) modeled farm and ani- 


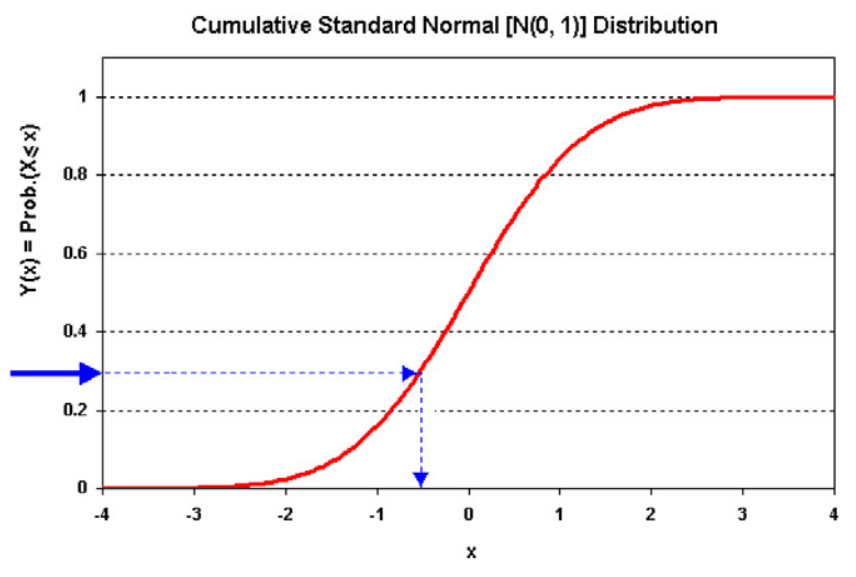

Figure 1. A representative mapping of outcomes of a normal distribution with a 0 mean and a SD of 1 , also known as a cumulative distribution function. The values on the vertical axis are interpreted as probabilities. In the case of the blue arrow, approximately 0.30 , there is a $30 \%$ probability of observing values on the $x$-axis of 0.5 or less. See online version for figure in color.

mal characteristics found in over 7 million Dairy Herd Improvement Association records (DHIA) as determinates in the cull decision of dairy cows. Cow data was from DHIA records supplied to those authors by Dairy Records Management Systems (DRMS, Raleigh, NC). States represented in the data set were Maine, New Hampshire, Pennsylvania, and Vermont (1993 to 1999); and New York (1996 to 1999), Illinois, Iowa (19961999), Indiana (1993-1999), Michigan (1997-1999), and Wisconsin (1995-1999), all within the United States

As stated, the probit model is constructed such that the dependent variable is a function of the standard normal distribution with a mean of 0 and a SD of 1 , $[\sim \mathrm{N}(0,1)]$. The portion of the model that holds the independent, right-hand side variables is represented by $z$ and identified here as $I$ in Eq. [1]. Equation [1] looks much like a standard OLS form: a constant term plus the sum of a vector of coefficients multiplied by their associated independent variables derived from the GLM:

$$
I=c_{0}+b_{1} x_{1}+b_{2} x_{2}+\ldots+b_{n} x_{n},
$$

in which $c_{0}$ is the regression constant, $b_{i}$ is the vector of coefficients, and $x_{i}$ is the vector of independent variables.

However, this part of the formulation is the numerator of the exponent to the $e$ term in Eq. [2]. This mathematical formulation being different from the OLS requires estimation of the solution by other means.

As a nonlinear form, the probit model is estimated using the maximum likelihood method. Also, due to its form, the coefficient estimates differ in their interpretation from the typical OLS estimates. The $I$ is the distance in $\mathrm{SD}$ from the mean of 0 and is determined by any value between negative and positive infinity, none of which result in a $P_{i}$ (dependent variable) greater than 1 or less than 0 . Graphically, the predicted dependent variable $I$ becomes
$P_{i}$, a probability represented by the values of vertical axis identified on the CDF (Fig. 1). Positive coefficient estimates of the $b_{i}$ 's indicate that the corresponding variables have a positive effect on increasing the probability $P_{i}$. The opposite is true for negative coefficient estimates.

$$
P_{i}=P\left[z \leq I_{i}\right]=\int_{z=-\infty}^{z=I}(2 \pi)^{-1 / 2} e^{-z^{2} / 2}
$$

Model estimations are accomplished using a subroutine package in SHAZAM (Whistler et al., 2007), an econometric software program. Once estimates for the coefficients are obtained and substituted into the CDF, Eq. [1] and [2], individual predictions for the set of the independent variables $(x)$ may be generated. These predictions are calculated by integration. The $P_{i}$ for any individual $x$ becomes a particular prediction or probability of a specific heifer with that maturity having dystocia or being pregnant for the second time, depending on which is specified and estimated. The typical $r^{2}$ calculations are not valid for this statistical method, so a normalized success index (NSI) value (Hensher and Johnson 1981) is used to gauge the effectiveness of the predictive power of the coefficient estimates within the sample. This index is derived from the weighted ratios of correct and incorrect predictions of the estimated model (Whistler et al., 2007). The NSI and other associated measures of model accuracy are listed in Tables 1, 2, 4, and 5. Like an $r^{2}$, the larger the NSI value, the better the performance of the estimated regression in predicting the within sample outcomes.

\section{RESULTS AND DISCUSSION}

\section{Maturity Index and Target Weight as Predictors of Dystocia}

Six probit equations are estimated using dystocia as the dependent variable. Dystocia is measured as present if a heifer required any aid in giving birth without distinction for varying degrees of assistance. The presence of dystocia was recorded at the time of parturition. The presence of dystocia is identified as the number one (1) and its absence as zero (0). The degree of maturity measured by either MI or TW at the time of first breeding is used as the independent variable and specified as linear, quadratic, or cubic forms. The quadratic and cubic forms are included to capture any possible diminishing effects maturity has in relationship to dystocia. These 6 models (Eq. [3] to [8]) are evaluated using the student $t$ statistic; $P$-values (found in parenthesis beneath the coefficient estimates in the equations), with those at or below the 5\% level considered statistically significance; and the NSI score (Table 1). 
Table 1. A listing of the normalized success index values for the 6 probit models proposed as predictors of dystocia. Each model is represented in the text in order of listing as Eq. [3], [4], [5], [6], [7], or [8]

\begin{tabular}{lc}
\hline \hline Form of maturity measure & Normalized success index \\
\hline $\mathrm{MI}^{2}$ & 0.030 \\
$\mathrm{MI}^{3}$ & 0.031 \\
$\mathrm{MI}^{4}$ & 0.032 \\
$\mathrm{TW}^{2}$ & 0.005 \\
$\mathrm{TW}^{3}$ & 0.006 \\
$\mathrm{TW}^{4}$ & 0.007 \\
\hline
\end{tabular}

${ }^{1} \mathrm{MI}=$ maturity index; $\mathrm{TW}=$ target weight.

${ }^{2}$ Linear variable.

${ }^{3}$ Squared variable.

${ }^{4}$ Cubed variable.

The coefficient estimates are statistically significant for each of the MI model forms but not with any of the TW models. The ranking of the 6 models using NSI scores are captured in Table 1. These results indicate very little difference among the $3 \mathrm{MI}$ equations, each separated by only a one-hundredth of a NSI score. The TW equations have a much smaller NSI score but show an identical pattern in ranking. The cubic form of the MI model, Eq. [5], has the largest NSI score.

$$
\begin{aligned}
& I_{D 1}=\underset{(<0.01)}{3.559-\underset{(<0.01)}{0.0689} \mathrm{MI}}, \\
& I_{D 2}=\underset{(<0.01)}{1.504}-\underset{(<0.01)}{0.000575 \mathrm{MI}^{2}},
\end{aligned}
$$

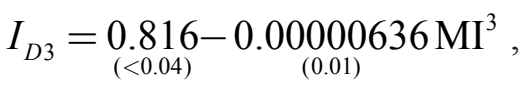

$$
\begin{aligned}
& I_{D 4}=\underset{(0.11)}{0.498}-\underset{(0.49)}{0.0207 \mathrm{TW}^{1},} \\
& I_{D 5}=\underset{(0.93)}{-0.0307-\underset{(0.08)}{0.000199} \mathrm{TW}^{2}, \quad \text { and }} \\
& I_{D 3}=\underset{(0.06)}{0.209}-\underset{(0.41)}{0.0000025 \mathrm{TW}^{3}},
\end{aligned}
$$

in which, for $I_{D i}, i=\{1,2,3,4,5,6\}$ - distance the value is from its mean, assuming a $\sim \mathrm{N}(0,1)$ distribution; $\mathrm{MI}$ is the maturity index, a measure of maturity; and TW is the target weight, a method of measuring maturity.

Equations [3] to [5] each in combination with Eq. [2] are used to estimate the predicted probability of dystocia for the MI scores over the range of 50 to 70.5 (Table 3). The resulting predictions for the 3 models are graphed in Fig. 2. This visual provides insight into the effect of the
Table 2. Statistical significance and the normalized success index (NSI) score of the 2 models developed by the 2 methods used to relate dystocia effects on second pregnancy rates. Method 1-Eq. [9] in the text—uses the actual observations in binary form, where 1 represents the occurrence of dystocia and 0 a nonevent. Method 2 -Eq. [10] - uses continuous probability value forecasts based on each heifer's maturity index, estimated by Eq. [3]

\begin{tabular}{lcc}
\hline \hline Heifer maturity measure & Coefficient $P$-values & NSI scores \\
\hline Method 1 & $<0.01$ & 0.046 \\
Method 2 & $<0.04$ & 0.066 \\
\hline
\end{tabular}

different model forms and how they vary in predicting the probability of dystocia. The predicted probabilities of dystocia are quite similar to each other over the range of MI found in the data, which is not surprising given the similar NSI scores.

Surprisingly, the linear form of the dystocia probit shows the most curvature at its upper and lower ends. This may seem counterintuitive as linear models generally reflect a straight line. The curvature in this case is not related to the linear nature of the $I$ portion of the equation but the exponential form of the overall model in deriving the $P_{i}$. The number of heifers with maturities greater than $71 \%$ of true mature weight at the time of breeding is limited to 11 , with the most mature having a maturity of $84.37 \%$, making it difficult to say anything definitive about what the natural rate of dystocia might be. As a complex health issue, dystocia can be caused by varying factors other than maturity (Zaborski et al., 2009). It is expected that dystocia will occur at some "natural" rate greater than 0 independent of maturity.

\section{Predicting Second Pregnancy}

Unlike first pregnancy (Stockton et. al., 2013) and dystocia, MI is not found to be a statistically significant forecaster of second pregnancy. However, the occurrence of dystocia at first calving is a significant predictor of successful rebreeding rates and, as expected, has a negative effect, shown by Eq. [9]. In this case, the dependent variable is assigned a value of (0) for a nonpregnant diagnosis and (1) for a positive diagnosis. The independent variable, dystocia, being a binary qualitative variable, is modeled in like manner with an assigned value of 1 for its presence and 0 for its absence. Unlike the previous probit regressions, the resulting model is not based on a continuous variable. As a binary choice variable, the outcome is interpreted as a single occurrence with a discrete 1-time effect on the second pregnancy rate and represents an average effect. The average effect of dystocia on the second breeding rate, $I_{\mathrm{PG} 2}$, effectively separates 
Table 3. A listing of relevant maturity indices (MI) and their associated predicted probabilities of dystocia rates as predicted by the 3 models estimated to forecast this event. Maturity index is used linearly and quadratically and in cubic specifications, listed in the text as Eq. [3], [4], and [5], respectively

\begin{tabular}{|c|c|c|c|}
\hline $\begin{array}{l}\text { Sample } \\
\text { MI }\end{array}$ & $\begin{array}{l}\text { Linear } \\
\text { MI (3) }\end{array}$ & $\begin{array}{l}\text { Quadratic } \\
\text { MI (4) }\end{array}$ & $\begin{array}{l}\text { Cubic } \\
\text { MI (5) }\end{array}$ \\
\hline 50.0 & 0.55 & 0.53 & 0.51 \\
\hline 50.8 & 0.52 & 0.51 & 0.49 \\
\hline 51.6 & 0.50 & 0.49 & 0.48 \\
\hline 52.4 & 0.48 & 0.47 & 0.46 \\
\hline 53.2 & 0.46 & 0.45 & 0.44 \\
\hline 54.0 & 0.44 & 0.43 & 0.43 \\
\hline 54.8 & 0.41 & 0.41 & 0.41 \\
\hline 55.6 & 0.39 & 0.39 & 0.39 \\
\hline 56.4 & 0.37 & 0.37 & 0.37 \\
\hline 57.2 & 0.35 & 0.35 & 0.35 \\
\hline 58.0 & 0.33 & 0.33 & 0.34 \\
\hline 58.8 & 0.31 & 0.31 & 0.32 \\
\hline 59.6 & 0.29 & 0.30 & 0.30 \\
\hline 60.4 & 0.27 & 0.28 & 0.28 \\
\hline 61.2 & 0.26 & 0.26 & 0.26 \\
\hline 62.0 & 0.24 & 0.24 & 0.24 \\
\hline 62.8 & 0.22 & 0.22 & 0.22 \\
\hline 63.6 & 0.21 & 0.21 & 0.21 \\
\hline 64.4 & 0.19 & 0.19 & 0.19 \\
\hline 65.2 & 0.18 & 0.17 & 0.17 \\
\hline 66.0 & 0.16 & 0.16 & 0.16 \\
\hline 66.8 & 0.15 & 0.14 & 0.14 \\
\hline 67.6 & 0.14 & 0.13 & 0.13 \\
\hline 68.4 & 0.12 & 0.12 & 0.11 \\
\hline 69.2 & 0.11 & 0.11 & 0.10 \\
\hline 70.0 & 0.10 & 0.09 & 0.09 \\
\hline 70.8 & 0.09 & 0.08 & 0.07 \\
\hline
\end{tabular}

the underlying effect maturity has on the second pregnancy. Evaluating Eq. [9] using the formula of the CDF indicates the second pregnancy rate for the average cow is $94.98 \%$ without the presence of dystocia and $84.31 \%$ with its presence. This result indicates that the fertility of cows in this study that experienced calving difficulty at first parturition is $10.67 \%$ less than cows not experiencing calving difficulty:

$$
I_{\mathrm{PG} 2}=\underset{(<0.01)}{1.645}-\underset{(<0.01)}{0.637} \mathrm{D}
$$

in which $I_{\mathrm{PG} 2}$ is the distance the value is from its mean, assuming a $\sim \mathrm{N}(0,1)$ distribution, and $D$ is a binary variable indicating the presence of dystocia ( 0 or 1$)$.

If dystocia rates are somehow made continuous, rather than binary, and then used to estimate the second pregnancy, that model would be continuous providing

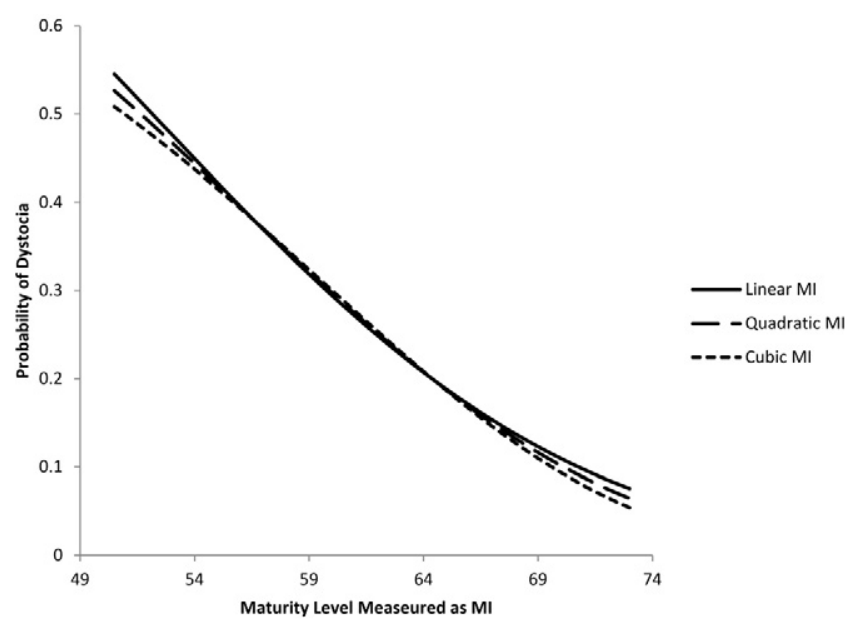

Figure 2. Predicted dystocia rates, where the probabilities of their occurrence are listed on the vertical axis and graphically mapped with the corresponding maturity index (MI) measures from Eq. [3], [4], and [5], respectively, for the linear, quadratic, and cubic specifications of the MI models on the horizontal axis.

varying probabilities of second pregnancy based on probabilities of dystocia. Equations [3], [4], and [5] from the previous analysis do exactly that: they provide predictions or imputations of dystocia as a discrete continuous variable. By substituting the imputed probabilities of dystocia in place of the binary dystocia measures, the resulting model, Eq. [10], reflects second pregnancy rates predicted by varying chances of dystocia, which are a function of maturity as measured by MI, making second pregnancy rates indirectly a function of MI. As indicated by the $P$-values, in parenthesis below the coefficients, both models are statistically significant at the 5\% level. A visual verification and illustration of the difference between the methods outcomes are graphed in Fig. 3 and 4:

$$
I_{\mathrm{PG} 2}=\underset{(<0.01)}{1.8531}-\underset{(<0.04)}{0.0165} \hat{D}_{c},
$$

in which $I_{\mathrm{PG} 2}$ is the distance the value is from its mean, assuming a $\sim \mathrm{N}(0,1)$ distribution, and $\hat{D}_{\text {c }}$ is a continuous variable for dystocia, predicted by MI using Eq. [4] and [2].

Figure 3 contrasts the difference in the predictions of second pregnancy between the 2 models described above. While this is not an appropriate application of Eq. [9], it provides insight into the maturity effect on second pregnancy through its effect on dystocia.

Equation [9] results in limited variation in expected second pregnancy rates ranging from 94.31 to $90.78 \%$. This is much less than the range of 94.98 to $84.31 \%$ found with Eq. [10]. Both methods are illustrative of the negative relationship between maturity and calving difficulty.

The interrelationship between the MI and dystocia is evident from Eq. [3] to [5] as is that between dystocia and the second pregnancy rate from Eq. [9] and [10]. 


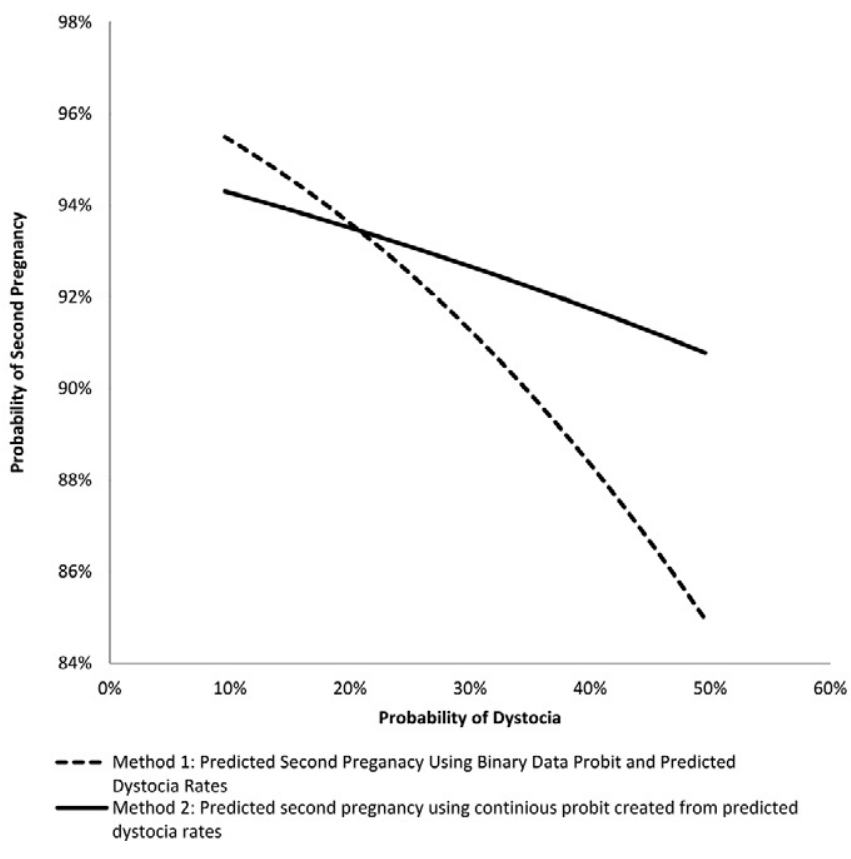

Figure 3. Predicted second pregnancy rates, listed as the probabilities of its occurrence on the vertical axis and graphically mapped as a function of probability measures of dystocia using Eq. [9] and [10] and the range of dystocia probabilities estimated from the experimental data range.

By mapping Eq. [10] results, second pregnancy probabilities, on the $y$-axis with the MI values substituted for the appropriate dystocia probabilities on the $x$-axis, the indirect effect of MI on second pregnancies is shown (Fig. 4). As expected, second pregnancy rates increase, although at a decreasing rate, as MI increases.

In addition to these visual illustrations, NSI scores and statistical measures are used to determine the effectiveness and relevance of the 2 models. Both methods have significance for all parameters at the $95 \%$ level as shown in Table 2. Method 2 loses significance for its variable term at the $97 \%$ confidence level but has a higher NSI score; that is, it predicts more accurately. Method 1 correctly predicts the average effect of cows becoming pregnant with their second calf having experienced dystocia. Method 2 predicts second pregnancy based on varying probabilities of dystocia based on maturity, in essence, the average effects of maturity on a cow's second pregnancy given the probability of dystocia for that maturity.

\section{Summary, Implications, and Discussion}

When comparing TW and MI, only MI significantly predicts dystocia, which has a direct effect on second pregnancy. Therefore, MI has an indirect effect on second pregnancy through its direct effect on dystocia. Combining findings from Stockton et al. (2013) with those in the current study, there is a link between a lower MI and a reduction in the chance of first pregnancy, an increased rate of dystocia, and, secondarily, a reduction

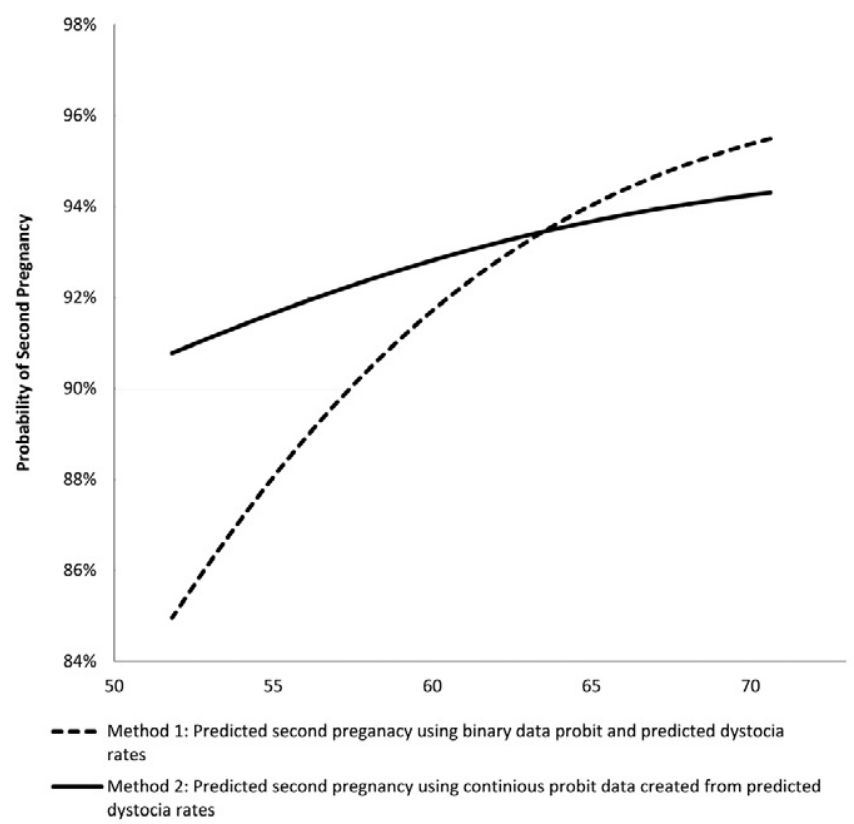

Figure 4. Predicted second pregnancy rates, listed as the probabilities of its occurrence on the vertical axis and graphically mapped in relation to heifer maturity measured by maturity index (MI) on the horizontal axis. The sample range of the MI are used to estimate dystocia rates using Eq. [3], which are then used in Eq. [9] and [10] to estimate the probabilities of second pregnancy providing the extended effect of MI on second pregnancy.

in the chance of second pregnancy. The biology is such that increases in the MI produce a smaller response in pregnancy rates and dystocia with each succeeding incremental increase, diminishing marginal productivity.

These decreasing relationships provide some basic understanding of why simple measures of maturity such as TW or MI alone are inadequate benchmarks for optimizing profitability. In addition to this inadequacy, TW has the additional problem of inaccuracy (Stockton et al., 2012). This is further complicated by the fact that heifers with the same MI do not necessarily have the same characteristics. While heifers with the same MI are predicted to have the same pregnancy and dystocia rates, they may differ in other ways such as dam size, age, and so on. These differences directly impact profitability by creating varying production costs and revenues for the same MI. Combine this fact with the diminishing marginal product of the biological relationships and it becomes clear that optimal profits do not just happen but are created by the factors and dynamics that are maximized at varying levels of maturity for different types of cattle, during different economic circumstances, and by varying management regimes.

These facts are indicative that the factors that contribute to MI (heifer age, birth weight, prebreeding weight, dam age and weight, and nutrition) combined with the specific economic realities and management environment become the basis for understanding costs and revenue since they are the primary drivers of the biological outcomes. 
Table 4. The actual predictions of the probit model of second pregnancy based on the observed binary dystocia occurrence for method 1, Eq. [9], shown in the normalized success index (NSI) table. The column heading indicates the model predictions and the row heading indicates actual events, where 1 is affirmation of occurrence and 0 is its absence. Success of the NSI is based on correct predictions of both occurrence and nonoccurrence

\begin{tabular}{lccccc}
\hline \hline & \multicolumn{3}{c}{ Model predicted outcomes } & \\
\cline { 2 - 4 } & & 0 & 1 & Count & Share \\
\hline Actual occurrences & 0 & 5 & 27 & 32 & 0.076 \\
& 1 & 52 & 336 & 388 & 0.924 \\
Prediction totals & 57 & 363 & 420 & \\
Predicted share & 0.14 & 0.86 & 1 & \\
Proportional success & 0.09 & 0.93 & 0.81 & \\
Success index & -0.05 & 0.06 & 0.046 & \\
\hline
\end{tabular}

To illustrate how the factors that control MI potentially alter productivity, 2 heifers from the same herd of varying prebreeding weights, ages, birth weights, dam mature weights and ages, and nutritional regimes, as described in Table 6 , are compared by pregnancy and dystocia rates. Heifer 1 weighs $340 \mathrm{~kg}$ while heifer 2 weighs $226 \mathrm{~kg}$ at prebreeding with a herd average mature weight of $521 \mathrm{~kg}$. The estimated TW percent for heifer 1 and 2 are 65 and $43 \%$, respectively, making the larger heifer meet the standard optimal breeding weight target and the smaller heifer underweight. However, the MI and associated predicted variables tell a different story. Considering all of the factors that make up a heifer's MI, Eq. [11], heifer 1 is found to have a MI score of 50 and heifer 2 is found to have a MI score of 60 . These scores are in opposition to the TW rankings, illustrating the difference between the 2 mea-

Table 5. The actual predictions of the probit model of second pregnancy based on the observed binary dystocia occurrence for method 2, Eq. [10], shown in the normalized success index (NSI) table. The column heading indicates the model predictions and the row heading indicates actual events, where 1 is affirmation of occurrence and 0 is its absence. Success of the NSI is based on correct predictions of both occurrence and nonoccurrence

\begin{tabular}{lccccc}
\hline \hline & \multicolumn{3}{c}{ Model predicted outcomes } & \\
\cline { 2 - 5 } & & 0 & 1 & Count & Share \\
\hline Actual occurrences & 0 & 18 & 14 & 32 & 0.076 \\
& 1 & 165 & 223 & 388 & 0.924 \\
Prediction totals & 183 & 237 & 420 & \\
Predicted share & 0.44 & 0.56 & 1 & \\
Proportional success & 0.1 & 0.94 & 0.57 & \\
Success index & -0.34 & 0.38 & 0.066 & \\
\hline
\end{tabular}

Table 6. The statistically significant heifer characteristics found in the maturity index (MI) Eq. [11] from Stockton et al. (2013) ${ }^{1}$ and respective values for the 2 example heifers used to illustrate the difference between using the MI or the target weight approach in forecasting pregnancies and dystocia as found in the summary, implications, and conclusions section

\begin{tabular}{lcc}
\hline \hline $\begin{array}{l}\text { MI heifer } \\
\text { characteristics }\end{array}$ & Heifer 1 & Heifer 2 \\
\hline Prebreeding weight, kg & 340 & 227 \\
Birth weight, kg & 43 & 31 \\
Prebreeding age, d & 390 & 443 \\
Mature dam weight, kg & 755 & 410 \\
Dam age, yr & 11 & 8 \\
Nutrition level & $2^{2}$ & $4^{2}$ \\
\hline 'Stockton et al. (2013) has a complete discussion of the 4 levels of nutri- \\
tion. \\
$\quad{ }^{2}$ Ration 1 has the highest level of nutrition followed by ration 2 and then 3 \\
and ration 4 has the least.
\end{tabular}

sures. The specific heifer characteristics that translate into these respective MI scores are listed in Table 6:

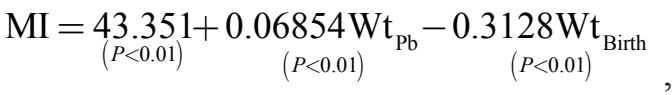

$$
\begin{aligned}
& +0.000089 \text { Age }_{\text {Heifer }}^{2}-0.02804 \mathrm{Wt}_{\text {Dam }} \\
& (P<0.01) \quad(P<0.0) \\
& +\underset{(P<0.03)}{1.756 \mathrm{Age}_{\mathrm{Dam}}-0.1448 \mathrm{Age}_{\mathrm{Dam}}^{2}} \\
& +4.888 T 1+2.645 T 2+2.588 T 3
\end{aligned}
$$

in which $\mathrm{MI}$ is the maturity index, $\mathrm{Wt}_{\mathrm{Pb}_{2}}$ is the prebreeding $\mathrm{BW}, \mathrm{Wt}_{\mathrm{Birth}}$ is the birth weight, $\mathrm{Age}^{2}{ }_{\text {Heifer }}$ is the prebreeding age (in days), $\mathrm{Wt}_{\mathrm{Dam}}$ is the mature $\mathrm{BW}$ of dam, $T 1$ is a dummy/indicator variable for the feed treatment group resulting in a traditional group average prebreeding BW of $58 \%$ of herd average, $T 2$ is a dummy/indicator variable for the feed treatment group resulting in a traditional group average prebreeding BW of $53 \%$ of herd average, and $T 3$ is a dummy/indicator variable for the feed treatment group resulting in a traditional group average prebreeding BW of $56 \%$ of herd average.

In addition to the prebreeding weight difference, the heifers also varied by 1 ) age (heifer 1 is $51 \mathrm{~d}$ younger than heifer 2); 2) birth weight (heifer 1 has a $13.15 \mathrm{~kg}$ heavier weight than heifer 2); 3) the dam's mature weight, which differs by $344 \mathrm{~kg}$ (heifer 1 having the heavier dam); 4) the dam's age (heifer 1 has a 10-yr-old dam and heifer 2 had a 6-yr-old dam); and 5) nutrition level after weaning before breeding, where heifer 1 was developed on a higher level of nutrition (ration T1) verses a medium level for heifer 2 (ration T3). While nothing here identi- 
fies the appropriate costs and revenues associated with these heifers, it is clear that feed intake and quality are different creating differences in direct cost.

With a MI score of 60 , heifer 2 is predicted to have a $97.4 \%$ chance of a positive first pregnancy diagnosis, and if she has a calf, she is predicted to have a $28 \%$ chance of dystocia and a $91.7 \%$ probability of a second pregnancy diagnosis. This compares to heifer 1, the larger heifer, with a MI score of 50 predicted to have an average positive first pregnancy diagnosis of $74.8 \%$, nearly $23 \%$ less than heifer 2. If this larger heifer has a calf, she faces a $54.5 \%$ probability of experiencing some type of dystocia, is twice as likely to experience dystocia, and is over $14 \%$ less likely to be diagnosed pregnant for the second time with an $83 \%$ chance of a positive outcome. This difference is also likely to result in varying costs and revenues. From this example, it is clear that TW and the MI approach predict very different expectations. But even with the added information provided by the MI, it is still unknown which is likely to be most profitable without the assignment of specific economic relationships and values. It is possible to construct a set of economic scenarios where either heifer would be equal or superior in producing profit to the other, further validating the point that the combination of biology, management, and markets together are what determine optimal profitability.

In the introduction, it was posited that producers wanting to make optimal profits would develop replacement heifers to the point where expected added revenue is as least as much if not more than the added costs, that is, where marginal costs equals marginal revenue (Epp and Malone, 1981). Using this concept and knowing the relationships among the biological factors and appropriately assigning cost and revenues, profits can be made optimal. This work provides a limited biological basis for building such a bioeconomic model where marginal revenues and costs may be discovered. Further investigation is needed to substantiate these findings to determine if they apply to other breeds and types of beef cattle and/ or to refine the relationships so reliable decision tools, models, or methodologies may be created, providing timely and valuable outcomes helping producers adjust and better manage their livestock systems and helping scientists to better direct and focus their research.

\section{LITERATURE CITED}

Basarab, J. A., L. M. Rutter, and P. A. Day. 1993. The efficacy of predicting dystocia in yearling beef heifers: II. Using discriminant analysis. J. Anim. Sci. 71:1372-1380.

Bellows, R. A., R. E. Short, D. C. Anderson, B. W. Knapp, and O. F. Pahnish. 1971. Cause and effect relationships associated with calving difficulty and calf birth weight. J. Anim. Sci. 33:407-415.
Cammack, K. M., M. G. Thomas, and R. M. Enns. 2009. Reproductive traits and their heritabilities in beef cattle. Prof. Anim. Sci. 25:517528.

Doyle, S. P., B. L. Golden, R. D. Green, and J. S. Brinks. 2000. Additive genetic parameter estimates for heifer pregnancy and subsequent reproduction in Angus females. J. Anim. Sci. 78:2091-2098.

Eler, J. P., J. A. Silva, J. B. Ferraz, F. Dias, H. N. Oliveira, J. L. Evans, and B. L. Golden. 2002. Genetic evaluation of the probability of pregnancy at 14 months for Nellore heifers. J. Anim. Sci. 80:951954.

Epp, D. J., and J. W. Malone Jr. 1981. Introduction to agricultural economics. Macmillian Publishing Co., Inc., New York.

Evans, J. L., B. L. Golden, R. M. Bourdon, and K. L. Long. 1999. Additive genetic relationships between heifer pregnancy and scrotal circumference in Hereford cattle. J. Anim. Sci. 77:2621-2628.

Feuz, D. M. 1991. The optimal pre-breeding target weight for replacement beef heifers. In: Proc. West. Agric. Econ. Assoc., Portland, OR. p. 518-524.

Funston, R. N., and G. H. Deutscher. 2004. Comparison of target breeding weight and breeding date for replacement beef heifers and effects on subsequent reproduction and calf performance. J. Anim. Sci. 82:3094-3099.

Greer, R. C., R. W. Whitman, R. B. Staigmiller, and D. C. Anderson. 1983. Estimating the impact of management decisions on the occurrence of puberty in beef heifers. J. Anim. Sci. 56:30-39.

Griffiths, W. E., R. C. Hill, and G. G. Judge. 1993. Learning and practicing econometrics. John Wiley \& Sons, New York.

Gujarati, D. N. 2003. Basic econometrics. 4th ed. McGraw-Hill Irwin Publishing Company Inc., New York.

Hadley, G. L., C. A. Wolf, and S. B. Harsh. 2006. Dairy cattle culling patterns, explanations, and implications. J. Dairy Sci. 89:2286-2296.

Hensher, D. A., and L. W. Johnson. 1981. Applied discrete choice modeling. Halsted Press, New York.

Kay, R. D. 1981. Farm management planning, control, and implementation. McGraw-Hill Book Company, New York.

Martin, J. L., K. W. Creighton, J. A. Musgrave, T. J. Klopfenstein, R. T. Clark, D. C. Adams, and R. N. Funston. 2008. Effect of prebreeding weight or progestin exposure before breeding on beef heifer performance through the second breeding season. J. Anim. Sci. 86:451-459.

Morrison, D. G., P. E. Humes, N. K. Keith, and R. A. Godke. 1985. Discriminant analysis for predicting dystocia in beef cattle. I. Comparison with regression analysis. J. Anim. Sci. 60:608-616.

Patterson, D. J., L. R. Corah, J. R. Brethour, M. F. Spire, J. J. Higgins, G. H. Kiracofe, J. S. Stevenson, and D. D. Simms. 1991. Evaluation of reproductive traits in Bos taurus and Bos indicus crossbred heifers: Effects of postweaning energy manipulation. J. Anim. Sci. 69:2349-2361.

Patterson, D. J., R. C. Perry, G. H. Kiracofe, R. A. Bellows, R. B. Straigmiller, and L. R. Corah. 1992. Management considerations in heifer development and puberty. J. Anim. Sci. 70:4018-4035.

Stockton, M. C., R. K. Wilson, D. M. Feuz, L. A. Stalker, and R. N. Funston. 2013. Using measurable physical characteristics to forecast beef heifer maturity: The identification of a maturity index. J. Anim. Sci. 91:4462-4468.

Stockton, M. C., R. K. Wilson, R. N. Funston D. M. Feuz, and L. A. Stalker. 2012. Heifer breeding maturity and its effects on profitability: Nebraska sandhills beef cattle. University of NebraskaLincoln research bulletin 350. http://ianrpubs.unl.edu/live/rb350/ build/rb350.pdf. (Accessed 9 September 2014.)

Whistler, D., K. J. White, and D. Bates. 2007. SHAZAM econometrics software version 10: User's reference manual. Northwest Econometrics, Ltd., Vancouver, BC, Canada.

Zaborski, D., W. Grzesiak, I. Szatkowska, A. Dybus, M. Muszynska, and M. Jedrzejczak. 2009. Factors affecting dystocia in cattle. Reprod. Domest. Anim. 44:540-551. 